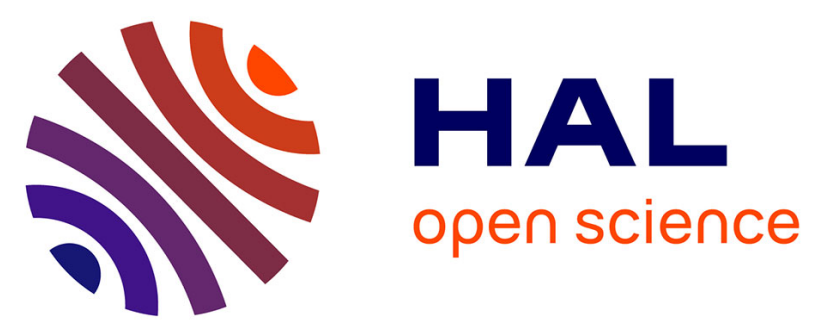

\title{
Development of On-Line Solid-Phase Extraction-Liquid Chromatography Coupled with Tandem Mass Spectrometry Method to Quantify Pharmaceutical, Glucuronide Conjugates and Metabolites in Water
}

\author{
Lea Bazus, Nicolas Cimetiere, Dominique Wolbert, Guy Randon
}

\section{To cite this version:}

Lea Bazus, Nicolas Cimetiere, Dominique Wolbert, Guy Randon. Development of On-Line Solid-Phase Extraction-Liquid Chromatography Coupled with Tandem Mass Spectrometry Method to Quantify Pharmaceutical, Glucuronide Conjugates and Metabolites in Water. Journal of Chromatography \& Separation Techniques, 2016, 7 (5), pp.1000337. 10.4172/2157-7064.1000337 . hal-01438201

\section{HAL Id: hal-01438201}

\author{
https://hal-univ-rennes1.archives-ouvertes.fr/hal-01438201
}

Submitted on 17 Jan 2017

HAL is a multi-disciplinary open access archive for the deposit and dissemination of scientific research documents, whether they are published or not. The documents may come from teaching and research institutions in France or abroad, or from public or private research centers.
L'archive ouverte pluridisciplinaire HAL, est destinée au dépôt et à la diffusion de documents scientifiques de niveau recherche, publiés ou non, émanant des établissements d'enseignement et de recherche français ou étrangers, des laboratoires publics ou privés. 
5 Léa Bazus $^{\mathrm{a}}$, Nicolas Cimetière ${ }^{*^{a}}$, Dominique Wolbert $^{\mathrm{a}}$ and Guy Randon ${ }^{\mathrm{b}}$

6 a Ecole National de Chimie de Rennes, CNRS, UMR 6226, 11 Allée de Beaulieu, CS 50837,

735708 Rennes Cedex 7, France

$8 \quad{ }^{c}$ Veolia Eau, Direction Technique Région Ouest, 8 allée Rodolphe Bopierre, 35020 Rennes

9 Cedex 9, France 
Abstract:

The present work describes the development of an analytical method, based on automated on-line solid phase extraction followed by ultra-high-performance liquid chromatography coupled with tandem mass spectrometry (SPE-LC-MS/MS) for the quantification of 37 pharmaceutical residues, covering various therapeutic classes, and some of their main metabolites, in surface and drinking water. A special attention was given to some glucuronide conjuguates and metabolites of active subtances. Multiple Reaction Monitoring (MRM) was chosen and two transitions per compound are monitored (quantification and confirmation transitions). Quantification is performed by standard addition approach to correct matrix effect. The method provides limit of quantification inferior to $20 \mathrm{ng} \cdot \mathrm{L}^{-1}$ for all compounds. The methodology was successfully applied to the analysis of surface water and drinking water of 8 drinking water treatment plant in west of France. The highest drug concentrations in surface water and drinking water were reported for ketoprofen, hydroxyibuprofen, acetaminophen, caffeine and danofloxacin.

Key words: pharmaceuticals, automated on-line solid phase extraction, liquid chromatography, tandem mass spectrometry, water analysis 


\section{Introduction}

Pharmaceuticals are an important group of emerging contaminants in the environment [1]. In recent years many reports have been made on the occurrence of the large, differentiated group of pharmaceuticals in wastewater, surface water, ground water and drinking water in many countries [2-9]. After administration, most pharmaceuticals are not completely metabolized. The unmetabolized parent pharmaceutical and some metabolites are subsequently excreted from the body via urine and faeces [10]. Reports have shown that many pharmaceuticals do not totally degrade during conventional wastewater treatment $[11,12]$. The concentrations of individual compounds in wastewater, surface water, ground water and drinking water are typically in the range of $\mathrm{ng} / \mathrm{L}$ to $\mu \mathrm{g} / \mathrm{L}$. The effect on long-term pharmaceutical residues in aquatic environments remains largely unknown. In addition, the risks to the environment are evaluated for a particular drug, while we find a mixture of all these compounds in aquatic environments. Studies have shown that combinations of drugs may be more powerful than the simple addition of two drugs individually toxic effects [1314].

Wastewater effluent is a major source for the input of pharmaceuticals to the environment [11;12], which can then migrate through water systems and into source water intended for drinking water supplies. Advanced wastewater treatment processes have been shown to significantly reduce the concentrations of emerging contaminants. However, some compounds are not completely removed even if treatment techniques are used [15]. Moreover, most of the WWTP do not include these specifically designed treatment units. In this context, sensitive analytical methods allowing the quantification of many pollutants at trace concentration is essential. Solid Phase Extraction (SPE) is the most commonly used technique to prepare sample before analysis. SPE allows the concomitance of analyte 
concentration and interferences removal $[16 ; 17]$. To date, most of the published multiresidue methods for the determination of ultra traces of pharmaceuticals compounds in surface and drinking water use off-line SPE followed by gas chromatography mass spectrometry (GC-MS) or by liquid chromatography-tandem mass spectrometry (LCMS/MS) $[2-5 ; 7 ; 9 ; 12]$. However, On-line Solid Phase Extraction is an emerging method for analysis of the trace compounds of organic micropollutants (reactive drugs, pesticides...). This technique has many advantages: saving time, automated method, reproducibility, very low solvent consumption, small sample handling, SPE cartridges reuse... [17]. The cartridges used to concentrate pharmaceuticals residues are usually Oasis ${ }^{\mathrm{TM}} \mathrm{HLB}$ or hydrophobic resins. [18;19]. This technique is generally coupled to liquid chromatography with UV, MS or MS/MS detector with reversed phase column [20-24].

The objectives of this work has been to develop a fully automated method to analyze a number of target compounds belonging to different therapeutical classes and some by product using on-line SPE directly coupled to liquid chromatography tandem mass spectrometry (LC-MS/MS). This analytical technique limits matrix effect impact. However remaining, interfering species can affect the analytical train, especially natural organic matter may coeluate with targeted compounds which leads to a signal disturbance causing over/underestimation or false positive results, or some compounds may react with targeted molecules during sampling and storage [25].

This method was evaluated in different water matrices: UltraPure Water (UPW) to develop the analytical method, surface water and drinking water for validation.

\section{Material and methods}

\subsection{Compound selection}


32 pharmaceuticals and 3 metabolites and 2 glucuronide conjugates were selected for this study (Table 1 and Table S1). These molecules were chosen based on the following criteria: i) selected compounds should exhibit a variety of physical properties, such as functional groups and polarity, ii) they should represent of a diversity of pharmaceutical classes, iii) high frequencies of environmental occurrence, iv) low removal efficiencies by drinking water and wastewater treatment techniques in France or others countries [2-9]. Table 1 lists the 37 molecules selected for our study and their optimized parameters for quantification, chemical structure is provided in the figure S1 in Supporting Information. Thereafter, the molecules will be called by the short identifiers which are given in the table 1 . The pharmaceutical classes represented are cardiovascular drugs, anticancer agents, human or veterinary antibiotics, neuroleptics, non-steroidal anti-inflammatory drugs and hormones.

\subsection{Pharmaceutical standards and reagents}

All pharmaceutical compounds have minimum 90\% purity, used as received in solid form and were obtained from Sigma Aldrich (FRANCE). Ultra pure water (UPW) was delivered by a ElgaPureLab System (resistivity $18.2 \mathrm{M} \Omega . \mathrm{cm}, \mathrm{COT}<50 \mu \mathrm{g} \mathrm{C} / \mathrm{L}$ ). Chromatographic and SPE solvents, acetonitrile ( $\mathrm{ACN}$ ) with or without $0.1 \%$ formic acid $(\mathrm{FA})$ and methanol (MeOH) were purchased from JT Baker (LC-MS grade) and were used in association with UPW in also or not with $0.1 \%$ formic acid.

All concentrated stock solution of individual pharmaceuticals were prepared in methanol with a concentration of $500 \mathrm{mg} \cdot \mathrm{L}^{-1}$ and stored at $-20{ }^{\circ} \mathrm{C}$. The mixed spiking solutions were prepared in methanol at $500 \mu \mathrm{g} \cdot \mathrm{L}^{-1}$ and stored at $4{ }^{\circ} \mathrm{C}$ during 15 days maximum. This mixed spiking solution is daily diluted in water to obtained $500 \mathrm{ng} \cdot \mathrm{L}^{-1}$ before use for standard 
addition. Concentrations prepared for analytical development and to quantify the target compounds in the different matrices are: 5, 10, 20, 50, 100, 250 and 500 ng.L ${ }^{-1}$.

\subsection{On-line solid phase extraction and liquid chromatography}

The analytical system consists of an automated SPE sampler coupled with an LC-MS/MS. The online extraction was carried out using a 2777 autosampler equipped with two parallel

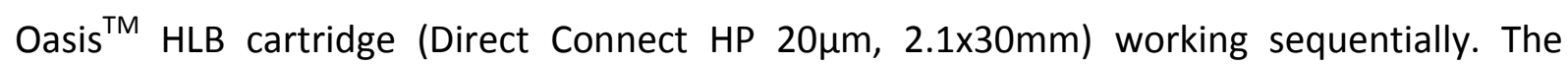
switching from the loading flow pattern, to elution, then conditioning and back to loading is performed using two six positions Everflow ${ }^{\mathrm{TM}}$ valves. Loading eluent (UPW) and conditioning eluent (methanol) were provided by a quaternary pump (Acquity ${ }^{\top M} \mathrm{QSM}$ ). Elution of the analytes from the SPE cartridge to LC system was achieved by connected the cartridge to the inlet of the separation column and using the initial chromatographic elution solution.

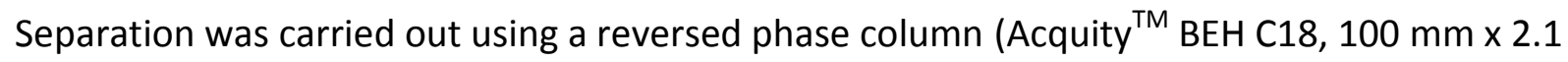
$\mathrm{mm}$ ID, $17 \mu \mathrm{m})$ placed in an oven $\left(45^{\circ} \mathrm{C}\right)$. The elution gradient was produced by a binary pump (Acquity ${ }^{\mathrm{TM}}$ BSM) and was optimized and will be described later in the manuscript.

\subsection{Mass spectrometry}

The mass spectrometer (Quattro Premier, Micromass ${ }^{\mathrm{TM}}$ ) operates with the following

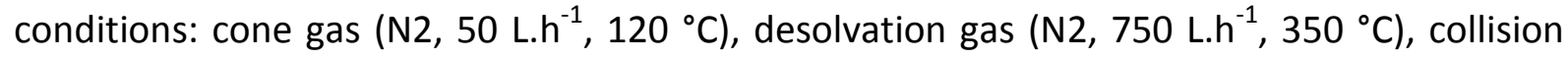
gas (Ar, $\left.0.1 \mathrm{~mL} \cdot \mathrm{min}^{-1}\right)$, capillary voltage (3000V). The ionization source of the mass spectrometer is an electrospray (ESI) used either in the positive or the negative mode according to pharmaceutical compounds structure (table 1). All the analysis, are made in "multiple reaction monitoring" (MRM) mode, the parent ion from the ESI source is selected in the first quadrupole (pseudomolecular ion in most cases) and fragmented in the collision 
128 cell. One or more fragments (quantification ion and, when available, confirmation ions) are 129 then selected by the third quadrupole before being detected by a photomultiplier. This 130 mode allows high sensitivity and selectivity. 


\begin{tabular}{|c|c|c|c|c|c|c|c|c|c|c|c|c|c|}
\hline Pharmaceutical class & Molecule (short identifier) & $\mathrm{N}^{\circ} \mathrm{CAS}$ & $\begin{array}{c}\mathrm{MW} \\
(\mathrm{g} / \mathrm{mol})\end{array}$ & $\begin{array}{l}\text { formula of the active } \\
\text { substance }\end{array}$ & ESI & $\begin{array}{l}\text { Parents } \\
\text { ion }\end{array}$ & $\begin{array}{c}\text { Daughter } \\
\text { ion(Q) }\end{array}$ & $\begin{array}{l}\text { Cones } \\
\text { (V) }\end{array}$ & $\begin{array}{l}\text { Collisions } \\
\text { (V) }\end{array}$ & $\begin{array}{l}\text { Confirmation } \\
\text { ion }\end{array}$ & $\begin{array}{l}\text { Collisions } \\
\text { (V) }\end{array}$ & $\begin{array}{c}\text { Dwell } \\
\text { time (ms) }\end{array}$ & $\begin{array}{c}\mathrm{Tr} \\
(\min )\end{array}$ \\
\hline \multirow{8}{*}{ Cardiovascular drugs } & Amlodipin (AML) & $111470-99-6$ & 567.05 & $\mathrm{C}_{20} \mathrm{H}_{25} \mathrm{ClN}_{2} \mathrm{O}_{5}$ & + & 409.6 & 238.1 & 18 & 11 & 409.6 & 13 & 50 & 4.03 \\
\hline & Atenolol (ATE) & 29122-68-7 & 266.34 & $\mathrm{C}_{14} \mathrm{H}_{22} \mathrm{~N}_{2} \mathrm{O}_{3}$ & + & 267 & 145 & 34 & 26 & 74 & 23 & 50 & 1.18 \\
\hline & Losartan (LOS) & $124750-99-8$ & 461 & $\mathrm{C}_{22} \mathrm{H}_{23} \mathrm{ClN}_{6} \mathrm{O}$ & + & 423.6 & 405.2 & 30 & 12 & 207 & 22 & 50 & 4.25 \\
\hline & Naftidrofuryl (NAF) & $03200-6-4$ & 473.56 & $\mathrm{C}_{24} \mathrm{H}_{33} \mathrm{NO}_{3}$ & + & 384.6 & 99.7 & 40 & 21 & 84.7 & 25 & 50 & 4.29 \\
\hline & Pravastatin (PRA) & $81131-70-6$ & 446.51 & $\mathrm{C}_{23} \mathrm{H}_{36} \mathrm{O}_{7}$ & - & 423.2 & 100.6 & 34 & 23 & 321.1 & 16 & 50 & 2.63 \\
\hline & Propanolol (PRO) & $525-66-6$ & 259.4 & $\mathrm{C}_{16} \mathrm{H}_{21} \mathrm{NO}_{2}$ & + & 260.2 & 116 & 34 & 18 & 183 & 18 & 50 & 3.33 \\
\hline & Gemfibrozil (GEM) & $25812-30-0$ & 250.33 & $\mathrm{C}_{15} \mathrm{H}_{22} \mathrm{O}_{3}$ & - & 249 & 121 & 34 & 23 & & & 50 & 4.95 \\
\hline & Trimetazidin (TRI) & $13171-25-0$ & 339.26 & $\mathrm{C}_{14} \mathrm{H}_{24} \mathrm{Cl}_{2} \mathrm{~N}_{2} \mathrm{O}_{3}$ & + & 267.4 & 180.9 & 21 & 16 & 165.8 & 26 & 50 & 1.18 \\
\hline \multirow{3}{*}{ anticancer agent } & Tamoxifen (TAM) & $10540-29-1$ & 371.5 & $\mathrm{C}_{26} \mathrm{H}_{29} \mathrm{NO}$ & + & 372.5 & 72 & 45 & 14 & & & 50 & 5.42 \\
\hline & Hydroxytamoxifen (OH-TAM) & $68047-06-3$ & 387.2 & $\mathrm{C}_{26} \mathrm{H}_{29} \mathrm{NO}_{2}$ & + & 388.2 & 72 & 45 & 14 & & & 50 & 4.58 \\
\hline & Ifosfamide (IFO) & $3778-73-2$ & 261 & $\mathrm{C}_{7} \mathrm{H}_{15} \mathrm{Cl}_{2} \mathrm{~N}_{2} \mathrm{O}_{2} \mathrm{P}$ & + & 261.02 & 153.95 & 25 & 22 & 92.04 & 25 & 75 & 3 \\
\hline \multirow{5}{*}{ Human Antibiotic } & Doxycycline (DOX) & $24390-14-5$ & 512.94 & $\mathrm{C}_{22} \mathrm{H}_{24} \mathrm{~N}_{2} \mathrm{O}_{8}$ & + & 445.5 & 428.2 & 30 & 18 & 153.8 & 28 & 50 & 2.95 \\
\hline & Erythromyicin (ERY) & $114-07-8$ & 769.96 & $\mathrm{C}_{37} \mathrm{H}_{67} \mathrm{NO}_{13}$ & + & 734.2 & 158 & 28 & 30 & 576.2 & 19 & 50 & 3.68 \\
\hline & Ofloxacin (OFX) & $82419-36-1$ & 361.37 & $\mathrm{C}_{18} \mathrm{H}_{20} \mathrm{FN}_{3} \mathrm{O}_{4}$ & + & 362 & 318 & 34 & 19 & 261 & 28 & 80 & 1.35 \\
\hline & Sulfaméthoxazole (SUL) & $723-46-6$ & 253.278 & $\mathrm{C}_{10} \mathrm{H}_{11} \mathrm{~N}_{3} \mathrm{O}_{3} \mathrm{~S}$ & + & 254 & 92 & 26 & 28 & 156 & 16 & 50 & 2.74 \\
\hline & Trimetoprime (TRP) & $738-70-5$ & 290.3 & $\mathrm{C}_{14} \mathrm{H}_{18} \mathrm{~N}_{4} \mathrm{O}_{3}$ & + & 291.2 & 230 & 24 & 24 & 261.1 & 26 & 50 & 1.18 \\
\hline \multirow{4}{*}{ Veterinarian Antibiotic } & Danofloxacin (DANO) & $112398-08-0$ & 357.38 & $\mathrm{C}_{19} \mathrm{H}_{20} \mathrm{FN}_{3} \mathrm{O}_{3}$ & + & 358.5 & 314 & 35 & 19 & 283 & 25 & 50 & 1.53 \\
\hline & Lincomycin (LINCO) & $859-18-7$ & 461.37 & $\mathrm{C}_{18} \mathrm{H}_{34} \mathrm{~N}_{2} \mathrm{O}_{6} \mathrm{~S}$ & + & 407.6 & 125.9 & 40 & 28 & 359.3 & 18 & 50 & 1.23 \\
\hline & Sulfadimerazine (SFZ) & $57-68-1$ & 278.33 & $\mathrm{C}_{11} \mathrm{H}_{12} \mathrm{~N}_{4} \mathrm{O}_{2} \mathrm{~S}$ & + & 279.4 & 185.9 & 29 & 16 & 91.7 & 26 & 50 & 1.91 \\
\hline & Tylosin (TYL) & $74610-55-2$ & 1066.19 & $\mathrm{C}_{46} \mathrm{H}_{77} \mathrm{NO}_{17}$ & + & 917 & 174 & 60 & 37 & 773 & 29 & 50 & 3.84 \\
\hline \multirow{4}{*}{ Neuroleptic } & Carbamazepine (CBZ) & $298-46-4$ & 236.27 & $\mathrm{C}_{15} \mathrm{H}_{12} \mathrm{~N}_{2} \mathrm{O}$ & + & 237.1 & 194 & 28 & 19 & 179 & 39 & 50 & 3.85 \\
\hline & Epoxycarbamazepine (Ep-CBZ) & $36507-30-9$ & 252.27 & $\mathrm{C}_{15} \mathrm{H}_{12} \mathrm{~N}_{2} \mathrm{O}_{2}$ & + & 253.3 & 179.9 & 28 & 28 & 236 & 12 & 50 & 3.2 \\
\hline & Oxazepam (OZP) & $604-75-1$ & 286.71 & $\mathrm{C}_{15} \mathrm{H}_{11} \mathrm{ClN}_{2} \mathrm{O}_{2}$ & + & 287.4 & 241 & 34 & 20 & 269.1 & 14 & 50 & 4.08 \\
\hline & Oxazepam (Glu-OZP) & 6801-81-6 & 462.84 & $\mathrm{C}_{21} \mathrm{H}_{19} \mathrm{ClN}_{2} \mathrm{O}_{8}$ & + & 463.2 & 287.1 & 26 & 15 & 269 & 26 & 15 & 3.34 \\
\hline \multirow{5}{*}{$\begin{array}{l}\text { Non-steroidal anti- } \\
\text { inflammatory drugs (NSAID) }\end{array}$} & Diclofenac (DICLO) & $15307-79-6$ & 294.14 & $\mathrm{C}_{14} \mathrm{H}_{11} \mathrm{Cl}_{2} \mathrm{NO}_{2}$ & + & 296.1 & 250 & 22 & 10 & 214.1 & 25 & 100 & 5.5 \\
\hline & Ibuprofen (IBU) & $15687-27-1$ & 206.28 & $\mathrm{C}_{13} \mathrm{H}_{18} \mathrm{O}_{2}$ & - & 205 & 161 & 17 & 7 & & & 50 & 4.06 \\
\hline & Hydroxyibuprofen (OH-IBU) & 51146-55-5 & 222.28 & $\mathrm{C}_{13} \mathrm{H}_{18} \mathrm{O}_{3}$ & - & 221.2 & 177 & 19 & 9 & 158.7 & 13 & 50 & 1.2 \\
\hline & Ketoprofen (KETO) & $22071-15-4$ & 254.28 & $\mathrm{C}_{16} \mathrm{H}_{14} \mathrm{O}_{3}$ & + & 255 & 209 & 29 & 12 & 105 & 22 & 100 & 4.14 \\
\hline & Salicylic acid (SCA) & $69-72-7$ & 138.12 & $\mathrm{C}_{7} \mathrm{H}_{6} \mathrm{O}_{3}$ & - & 137 & 92.6 & 30 & 14 & 64.7 & 28 & 70 & 1.16 \\
\hline \multirow{4}{*}{ Miscellaneous } & Acetaminophen (PARA) & $103-90-2$ & 151.16 & $\mathrm{C}_{8} \mathrm{H}_{9} \mathrm{NO}_{2}$ & + & 152 & 110 & 25 & 15 & 90 & 10 & 50 & 1.24 \\
\hline & Acetaminophen Glucuronide (Glu-PARA) & $16110-10-4$ & 327.29 & $\mathrm{C}_{14} \mathrm{H}_{17} \mathrm{NO}_{8}$ & + & 350 & 173.8 & 33 & 15 & & & & 1.64 \\
\hline & Caffeine (CAF) & $58-08-2$ & 194.19 & $\mathrm{C}_{8} \mathrm{H}_{10} \mathrm{~N}_{4} \mathrm{O}_{2}$ & + & 195.1 & 137.7 & 37 & 18 & 109.7 & 22 & 50 & 1.35 \\
\hline & Hydrochlorothiazide (HCTZ) & 58-93-5 & 297.74 & $\mathrm{C}_{7} \mathrm{H}_{8} \mathrm{ClN}_{3} \mathrm{O}_{4} \mathrm{~S}_{2}$ & - & 296.2 & 77.6 & 42 & 28 & 204.8 & 22 & 50 & 1.5 \\
\hline \multirow{4}{*}{ Hormone } & Ethyinylestradiol (EE) & 57-63-6 & 296.4 & $\mathrm{C}_{20} \mathrm{H}_{24} \mathrm{O}_{2}$ & - & 295.2 & 144.9 & 54 & 40 & 183 & 35 & 50 & 4.07 \\
\hline & $17 \beta$-Estradiol $(\beta E)$ & $50-28-2$ & 272.38 & $\mathrm{C}_{18} \mathrm{H}_{24} \mathrm{O}_{2}$ & - & 271.1 & 145 & 50 & 38 & 183 & 41 & 70 & 3.89 \\
\hline & Estrone (EO) & $53-16-7$ & 270.37 & $\mathrm{C}_{18} \mathrm{H}_{22} \mathrm{O}_{2}$ & - & 269.1 & 145 & 53 & 35 & 183 & 36 & 70 & 4.14 \\
\hline & Progesterone (PGT) & $57-83-0$ & 314.46 & $\mathrm{C}_{21} \mathrm{H}_{30} \mathrm{O}_{2}$ & + & 315.2 & 97 & 32 & 24 & 109 & 26 & 50 & 5.77 \\
\hline
\end{tabular}




\section{Results and discussion}

\subsection{Mass spectrometry optimization}

The selection of optimum detection parameters (collision energy, cone voltage, ionization mode) for each targeted compound was carried out by introducing a standard diluted single solute solution at $5 \mathrm{mg} \cdot \mathrm{L}^{-1}$ directly in the mass spectrometer (without separation). The pseudo-molecular ion $\left([\mathrm{M}+\mathrm{H}]^{+}\right.$or $\left.[\mathrm{M}-\mathrm{H}]^{-}\right)$was selected as the parent ion. Acetaminophenglucuronide was ionized as sodium adducts $\left([\mathrm{M}+\mathrm{Na}]^{+}\right)$and the daughter ion correspond to the sodium adduct of paracetamol obtained by the loss of glucuronic acid. Similar fragmentation pattern with loss of carbohydrate group was observed with Glu-OZP $\left([\mathrm{M}+\mathrm{H}]^{+}\right.$ $\left.\rightarrow[\mathrm{M}-\mathrm{Glu}+\mathrm{H}]^{+}\right)$. In some cases, the standard molecules were purchased as sodium or chloride salt so molecular weight of the commercial product indicated in the table 1 does not correspond to the formula of active compounds. So the molecular weights indicated in the table 1 do not correspond to the mass of the pseudo molecular ion (AML, LOS, NAF, PRA, TRI, DOX, ERY, LINCO and TYL). Positive mode was selected for most of the molecules and 8 analytes were ionized under negative mode because of their tendancy to loose a proton. Two transitions are chosen for quantification and confirmation. If possible transition corresponding to the loss of simples fragments (ie. $-\mathrm{H}_{2} \mathrm{O}$ or $-\mathrm{CO}_{2}$ ) has been prefered for quantification or confirmation transition. Only one transition could be found to 4 molecules: Ibuprofen, Gemfibrozil, Tamoxifen and Hydroxy-Tamoxifen. The results are presented in table 1.

\subsection{On-line SPE method development}


The efficiency of the SPE step was studied using two different types of SPE cartridge phases :

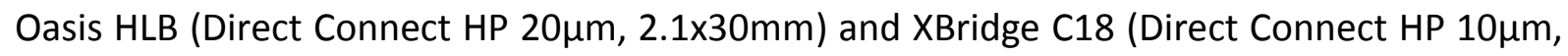
$2.1 \times 30 \mathrm{~mm})$. The low energie interactions are predominant with the C18 phases, unlike for HLB phases where the dipole-dipole interactions are brought into play. Table 2 presents characteristics (log(Kow), pka, coefficient of dissociation, dipolar moment) of molecules. The extraction yield was then calculated according to the following equation:

$$
\text { Extraction yield }(\%)=100 * \frac{\text { Area }_{\mathrm{SPE} \text { mode }}}{\text { Area }_{\text {conventional mode }}}
$$

For each compounds, the area obtained with the injection of $5 \mathrm{~mL}$ of solution at $100 \mathrm{ng} . \mathrm{L}^{-1}$ in SPE mode was compared to the area obtain in conventional mode $\left(\operatorname{Vinj}=5 \mu \mathrm{L} ; \mathrm{C}=100 \mu \mathrm{g} \cdot \mathrm{L}^{-1}\right)$.

The results are presented in figure 1. In a global overview the extraction yields are better with the Oasis HLB phase in comparison to the C18 phase. 11 molecules have slightly better extraction yields with the XBridge C18 media. Given these results, Oasis HLB phase was chosen for the SPE cartridges. The extraction yields are between $24 \%$ and $96 \%$. Six molecules, among them three hormones ( $A T E, T R I, D O X, E E, \beta E$ and EO) have extraction yields inferior or equal to $50 \%$ but the signal is sufficient for our analysis given the reproducibility of the extraction step. The loading time and flow rate influence the analyte retention onto the preconcentration cartridge. If the loading time is too short, a part of the molecules of interest will not be collected in the cartridge. $\mathrm{MeOH}$ is used for the cartridge conditioning during 3 minutes and UPW for the loading sample during 5.5 minutes at $2 \mathrm{~mL} / \mathrm{min} .5 \mathrm{~mL}$ of sample are injected onto the cartridge. Elution of our compounds is made using the initial chromatographic conditions. The preconcentration method takes 8.5 minutes. The $\mathrm{pH}$ of samples and eluents was also optimized to try to improve the extraction yields. The figure 2 shows the effect of $\mathrm{pH}(3,7$ and 9) on molecule's recovery yields. Most of 
the targeted compounds were efficiently extracted at neutral $\mathrm{pH}$ values. The recovery yields of thirteen molecules (LOS, GEM, TAM, OH-TAM, IFO, TYL, DICLO, PARA, CAF, CBZ, OZP, PGT and ERY) do not show significant pH dependence. ATE, NAF and LINCO were comparatively more recovered under neutral condition due to the amine/ammonium repartition for the low $\mathrm{pH}$ values. DANO and OFX are amphoteric molecules and exhibit higher recovery yields under acid extraction than under neutral conditions. AML and OFX have extraction yields superior to $100 \%$, the differences may be included within the experimental errors. Three hormones have a better extraction yields at basic $\mathrm{pH}$ while below $23 \%$ for an acid $\mathrm{pH}$. The SPE appears globally controlled by the carboxylic functions. The best compromise to our analytical method is the neutral $\mathrm{pH}$.

Tableau 2: $\log ($ Kow), pka, coefficient of dissociation and dipolar moment of molecules

\begin{tabular}{|c|c|c|c|c|}
\hline Molecule & Log(Kow) & pka & $\begin{array}{c}\text { coefficient of } \\
\text { dissociation }\end{array}$ & dipolar moment \\
\hline AML & 3 & 8.6 & $5.0010^{-5}$ & \\
\hline ATE & 0.16 & 9.6 & $1.5010^{-5}$ & 5.71 \\
\hline LOS & 1.19 & 5,5 & $8.8010^{-3}$ & \\
\hline NAF & 4.56 & 8.7 & $4.7010^{-5}$ & 2.83 \\
\hline PRA & 1.35 & 4.5 & $5.6010^{-3}$ & \\
\hline PRO & 3.48 & 9.5 & $1.7010^{-5}$ & \\
\hline GEM & 4.77 & 4.7 & $4.4010^{-3}$ & \\
\hline TRI & 1.04 & $4.3 / 8.9$ & $7.0010^{-3}$ & \\
\hline TAM & 3.24 & 8.76 & $4.2010^{-5}$ & \\
\hline OH-TAM & 4.74 & $3.2 / 6.4$ & $6.3010^{-4}$ & \\
\hline IFO & 0.86 & 13.2 & $2.5010^{-7}$ & \\
\hline DOX & 2,37 & $3.5 / 7.7$ & $1.4010^{-4}$ & \\
\hline ERY & 3,02 & 8.8 & $3.9010^{-5}$ & \\
\hline OFX & 0.65 & 6.1 & $9.4010^{-4}$ & 7.2 \\
\hline SUL & 0.79 & 5.7 & $1.4010^{-3}$ & \\
\hline TRP & 0.91 & 7.1 & $2.8010^{-4}$ & \\
\hline DANO & 0,44 & 6.0 & $9.9010^{-4}$ & \\
\hline LINCO & 0,56 & 7.6 & $1.6010^{-4}$ & \\
\hline SFZ & 0.19 & 7 & $3.2010^{-4}$ & 7.34 \\
\hline TYL & 1.63 & 7.7 & $1.4010^{-4}$ & \\
\hline CBZ & 2,77 & 7 & $1.0010^{-7}$ & 3.66 \\
\hline & & & & \\
\hline
\end{tabular}




\begin{tabular}{|c|c|c|c|c|} 
Ep-CBZ & 1.58 & 15.9 & $1.0010^{-8}$ & \\
\hline OZP & 2,24 & $1.7 / 11.6$ & $1.3010^{-1}$ & \\
\hline DICLO & 4,51 & 4 & $8.0010^{-3}$ & 4.55 \\
\hline IBU & 3,79 & 4.5 & $5.3010^{-3}$ & 4.95 \\
\hline OH-IBU & 3,97 & 4.8 & $3.9010^{-3}$ & \\
\hline KETO & 3.12 & 4.45 & $6.0010^{-3}$ & \\
\hline SCA & 1,19 & 3 & $3.1010^{-2}$ & \\
\hline PARA & 0,49 & 9.5 & $1.8010^{-5}$ & 4.55 \\
\hline CAF & -0.091 & 14 & $2.1010^{-1}$ & 3.71 \\
\hline HCTZ & $-0,07$ & 7.9 & $1.0010^{-4}$ & \\
\hline EE & 3,67 & 10.3 & $7.0010^{-6}$ & \\
\hline BE & 3.57 & 10.71 & $4.4010^{-6}$ & 1.56 \\
\hline EO & 3.69 & 10.4 & $6.0010^{-6}$ & 3.45 \\
\hline PGT & 4 & 18.9 & $3.5010^{-10}$ & \\
\hline
\end{tabular}

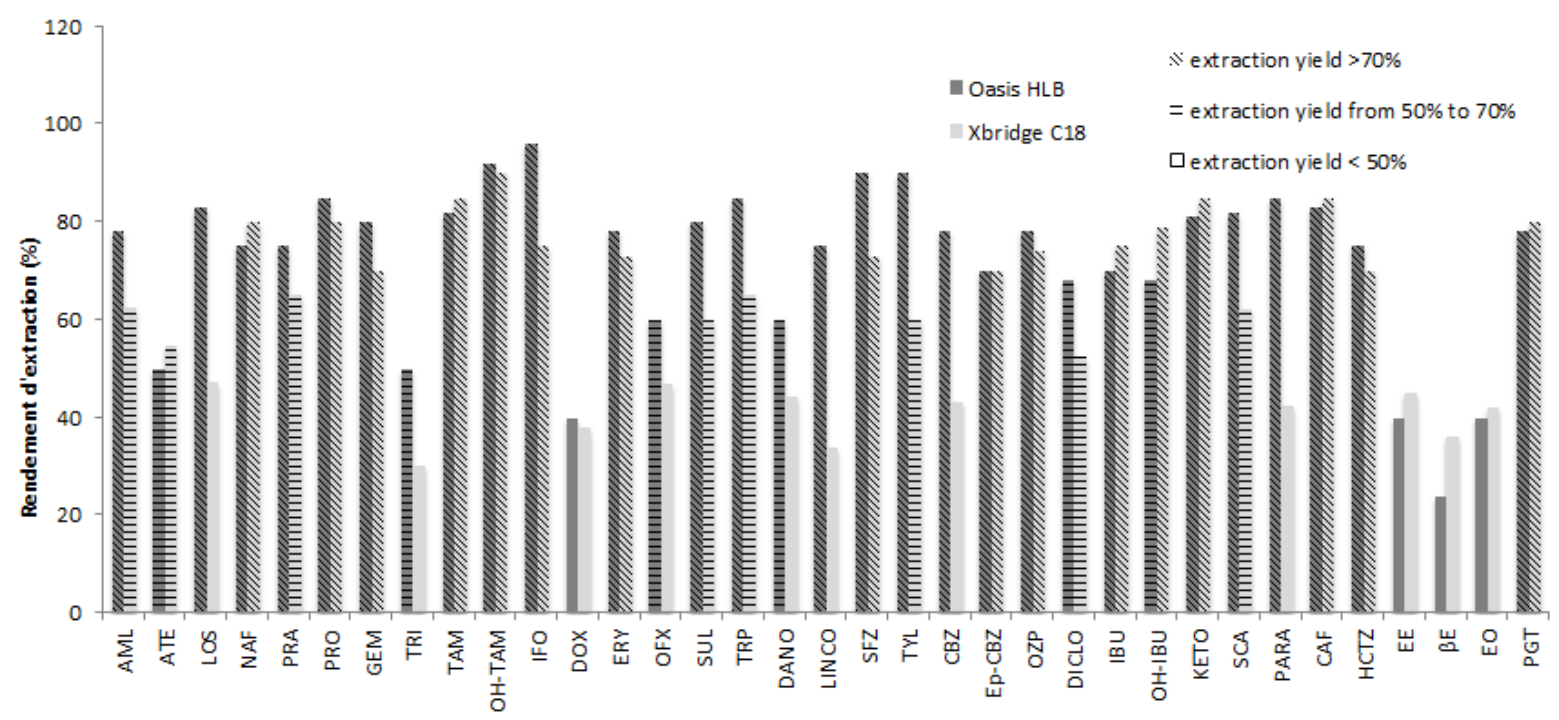

Figure 1: Extraction yields calculated for the two cartridges (Oasis HLB and Xbridge C18) tested for all 


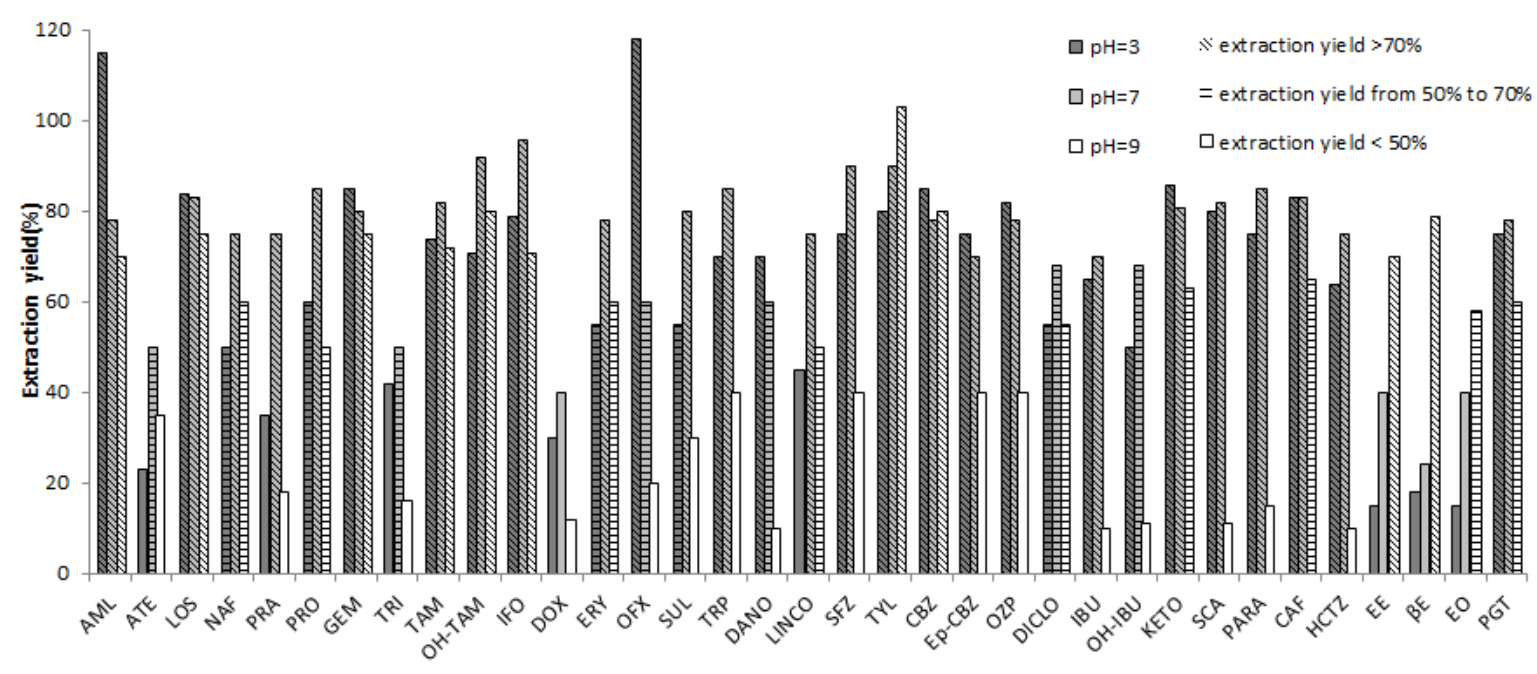

192

Figure 2: Extraction yields calculated for the $3 \mathrm{pH}(3,7$ and 9) for all analytes

\subsection{Chromatographic conditions}

Three chromatographic columns packed with different stationary phases were studied, two using the reversed phase mode: Acquity BEH C18 (100 mm x $2.1 \mathrm{~mm} \mathrm{ID}, 1.7 \mu \mathrm{m})$ and Acquity HSST3 (100 mm x $2.1 \mathrm{~mm} \mathrm{ID,} 1.7 \mu \mathrm{m})$. These two columns have the same stationary phase but Acquity HSST3 should allow for better separation of polar molecules due to the greater proportion of residual silanol groups. The third column has a polar stationary phase: BEH amide (100 mm x $2.1 \mathrm{~mm} \mathrm{ID,} 1.7 \mu \mathrm{m}$ ) in order to separate the analyte using hydrophilic interaction liquid chromatography (HILIC). Comparing the chromatograms obtained for the C18 and HSST3 column, the results are quite similar. Seven minutes are required to obtain sufficient separation. It should be underlined that the resolution between two consecutive peaks was quite low. However, because the quantification was done using different MRM channels this poor resolution does not affects the analytical performances.

Figure 3 summarizes the results by plotting the polarity (log Kow) as function of the capacity factor of the molecule, molecules with $k^{\prime}<1$ form the unretained groups with no $\log (\mathrm{kow})$ dependances. For the others, correlation between $k^{\prime}$ and $\log (k o w)$ shows two adverse 
behaviours in relation with the different stationary phase, BEH and HSST3 on the one part

210

211

212

213

214 and HILIC on the second part. Reversed phase HPLC columns (BEH C18 and HSST3) provide a satisfactory separation with $\mathrm{k}^{\prime}$ ranging from 0.93 to 9.91 according to the polarity of the considered compounds. However numerous analytes exhibit a high polarity and were poorly retained using reversed-phase HPLC. Normal phase HPLC column (BEH Amide) provides separation with $k^{\prime}$ ranging from 0.1 to 9.6. Molecules retained by the reversed phase HPLC column are not retained in normal phase HPLC with $k^{\prime}<1$. Moreover, peak tailing are observed for some molecules with HSST3 (SUL, GEM, DOX) and with HILIC column (PARA, DANO, HCTZ, TRI). The best compromise for our analyses is to use the BEH C18 column.

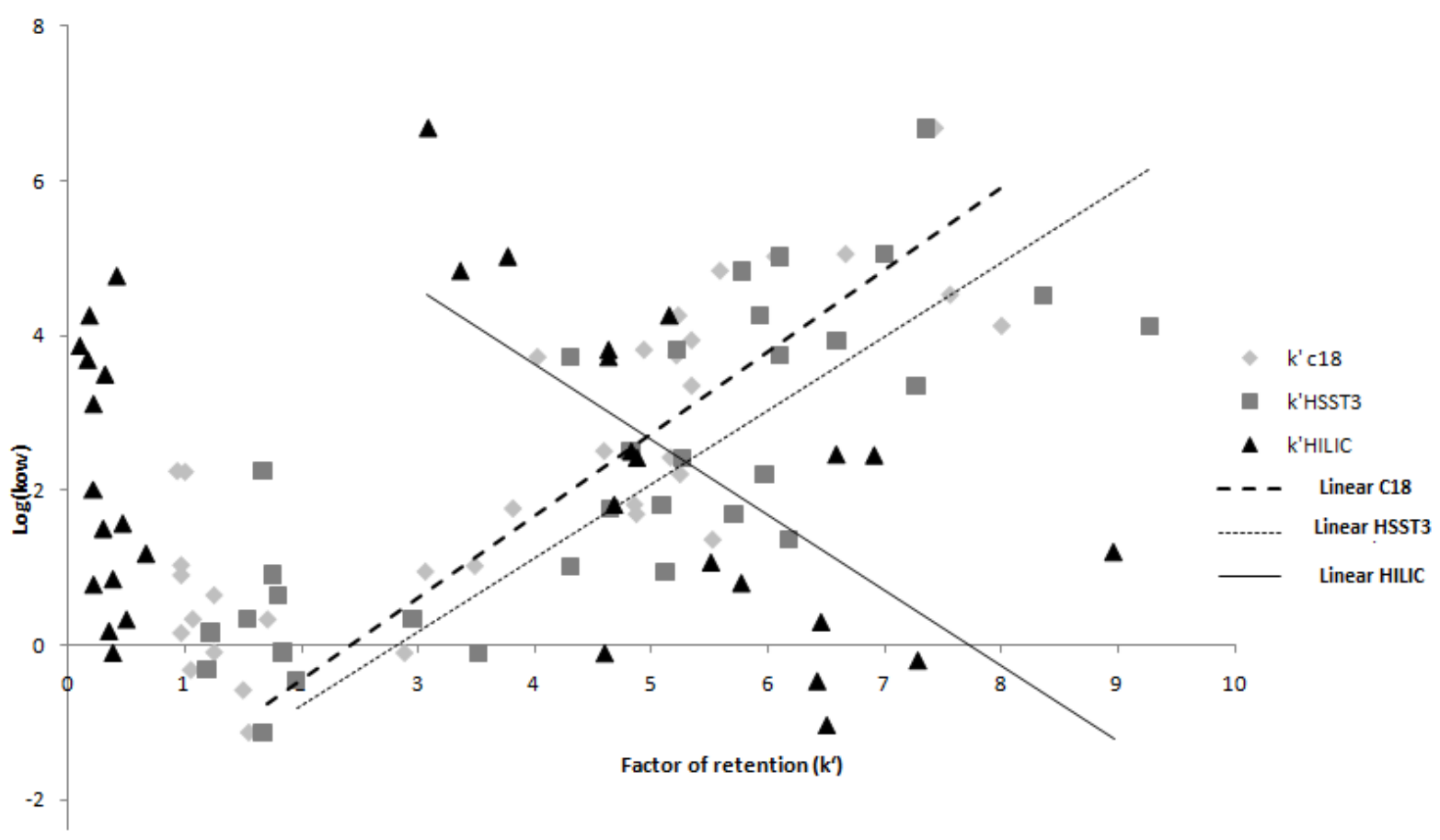

Figure 3: Polarity (log Kow) as function of the capacity factor for all molecules and for $\mathbf{3}$ chromatographic columns

223 The mobile phase flow rate was $0.4 \mathrm{~mL} \cdot \mathrm{min}^{-1}$, corresponding to the optimum zone of the Van 224 Deemter curve with this column [26]. The elution conditions were optimized. Two 225 chromatographic separation methods were needed to quantify all the target analytes. 

quantification even if the resolution is low.

a.

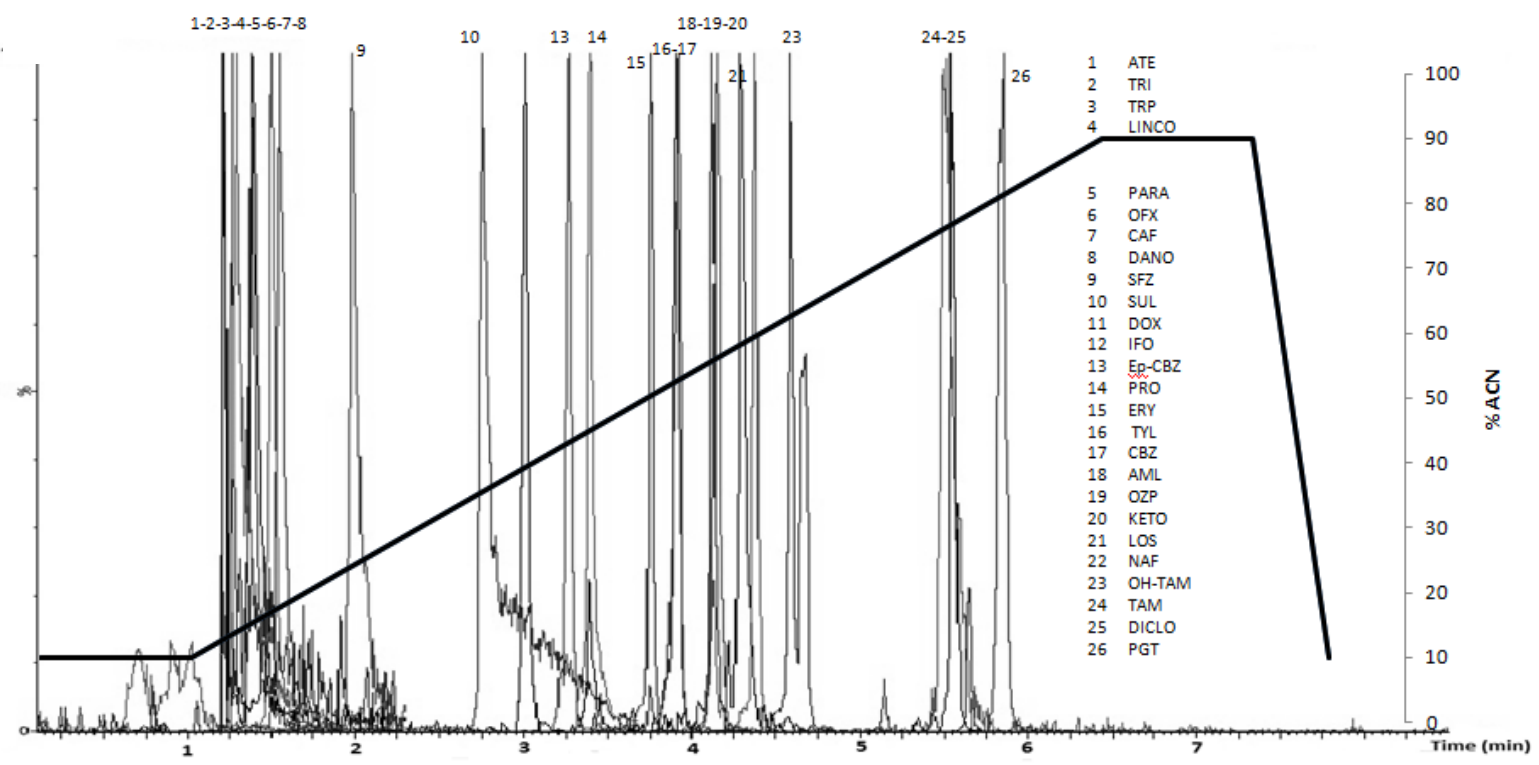

Indeed, analytes with ESI+ detection have better sensitivity with acidified eluents (with $0.1 \%$ of formic acid) unlike molecules with ESI- detection which have better sensitivity with neutral eluents. Moreover, the combination of both positive and negative ionization mode during the same run does lead to a decrease of the sensibility.

The elution conditions start with 20\% ACN/80\% UPW during 1 minute followed by a gradient 90\% ACN within 6 minutes and remain constant for $1 \mathrm{~min}$ before returning to initial conditions, details of the method are presented in Supporting information (Section B Figures S1-S3)

Examples of chromatograms obtained with a solution of $50 \mathrm{ng} \cdot \mathrm{L}^{-1}$ in UPW and the eluent program are presented in Figure 4.12 molecules elute within two minutes for the ESI+/acid eluent method. As mentioned above, the detection mode (MRM) allows an accurate 


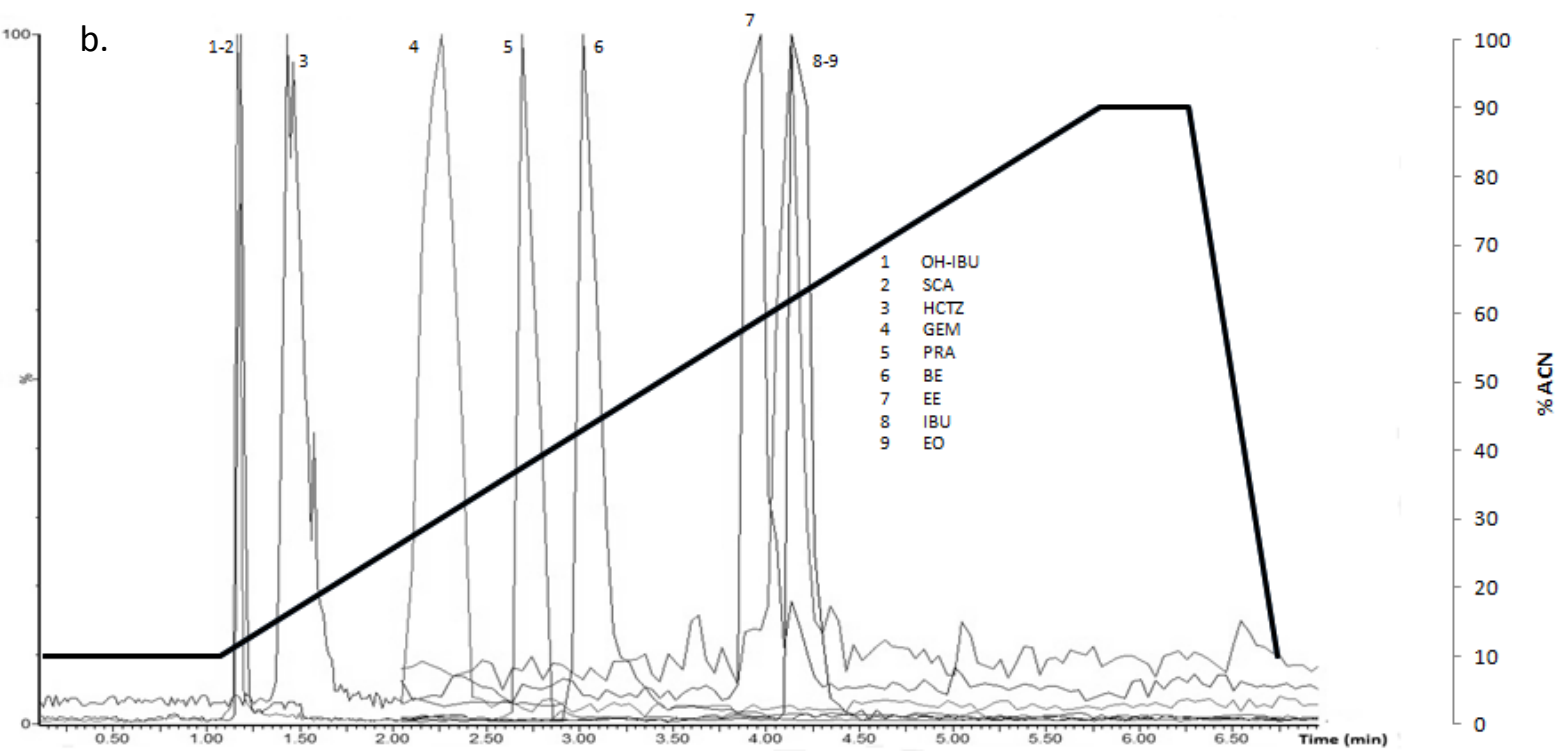

Figure 4: Chromatogram obtained at 50ng/L in UPW. a. first method with ESI+. b. Second method with ESI-

\subsection{Quantification limit and matrix effect}

Standard addition method was selected for calibration method in order to minimize or eliminated matrix effects. Figures 5 present examples of calibration curve for CBZ in UPW, Groundwater (GW), Drinking water (DW) and Surface water (SW). Limit of quantification (LOQ) were determined for all targeted compounds in UPW and GW with the equation given in figure 5a, in accordance with the AFNOR NF-T-90-210 norm for all analytes. GW could be considered free of pharmaceuticals residues because GW is drawn from a well recovering the waters on a small watershed without collective or on-site sanitation water release, and UPW can be considered as a matrix blank. Negatively ionized molecules (EO, BE, EE, HCTZ, SCA, IBU, OH-IBU, GEM, PRA) have higher limits of quantification because the background noise is more important than for $\mathrm{ESI}^{+}$. The values of the quantification limit of targeted compounds are presented in figure $6 \mathrm{a}$. LOQ values obtained range from 5 to $17 \mathrm{ng} / \mathrm{L}$. These limits of quantification are sufficient for our purpose. 
255 Measurement errors were incorporated by defining the $90 \%$ confidence intervals (figure $5 b$ ).

256 Figures $5 c$ and $d$ show standard addition calibration lines of CBZ in GW and DW.

257 Comparisons of the slopes obtained with real waters to the slope obtain in the blank

$258\left(\mathrm{a}_{G W} / \mathrm{a}_{U P W}\right.$ and $\left.\mathrm{a}_{\mathrm{DW}} / \mathrm{a}_{U P W}\right)$ allow a comprehensive approach of the matrix effects. These slope

259 ratios are presented in figure $6 \mathrm{~b}$ for all analytes. The matrix effect is a classical phenomenon

260 which can be very important in liquid chromatography coupled with mass spectrometry

261 because of the ionization process may be drastically influenced by the presence of

262 interfering species. Many studies have already described this phenomenon especially with

263 wastewaters. The presence of organic or inorganic substance can cause inhibition $(<1)$ or

264 enhancement $(>1)$ of a compound's signal [27-29]. In our case, natural organic matter may

265 disturb the SPE step or mass ionization so the rationalization of the slopes provides a global

266 overview of matrix effect but do not allow to identify the critical step.

267 In figure $6 b$, matrix effects are not significant when the ratio is close to 1 . In drinking water

268 this ratio was close to 1 for most of the analytes, only AML has a ratio superior to 5. 

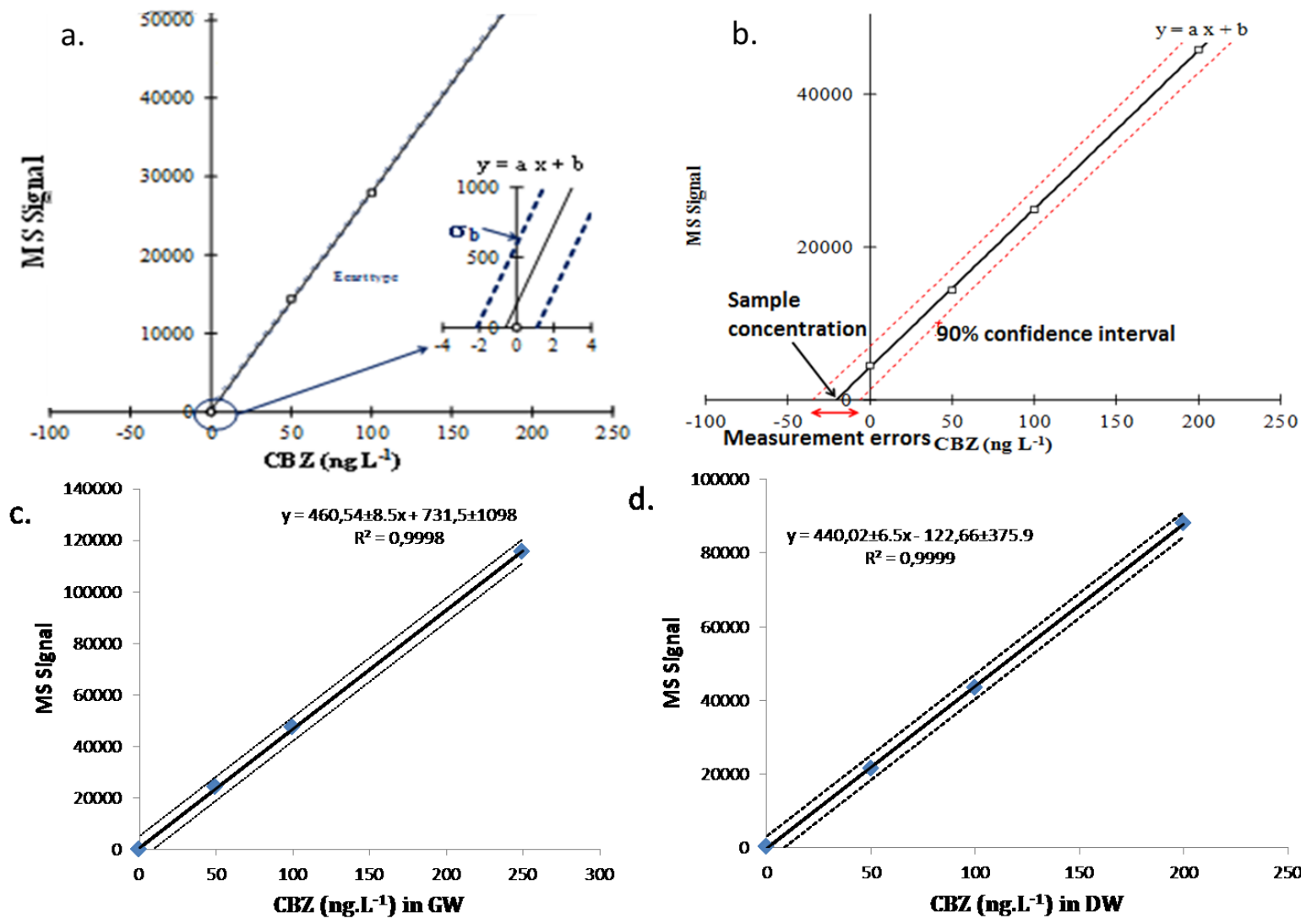

Figure 5: a. equation of LOQ determanation. b. Exemple of standard addition for CBZ with $90 \%$ confidence interval. c. and d. Exemple of standard addition in GW and DW for CBZ 

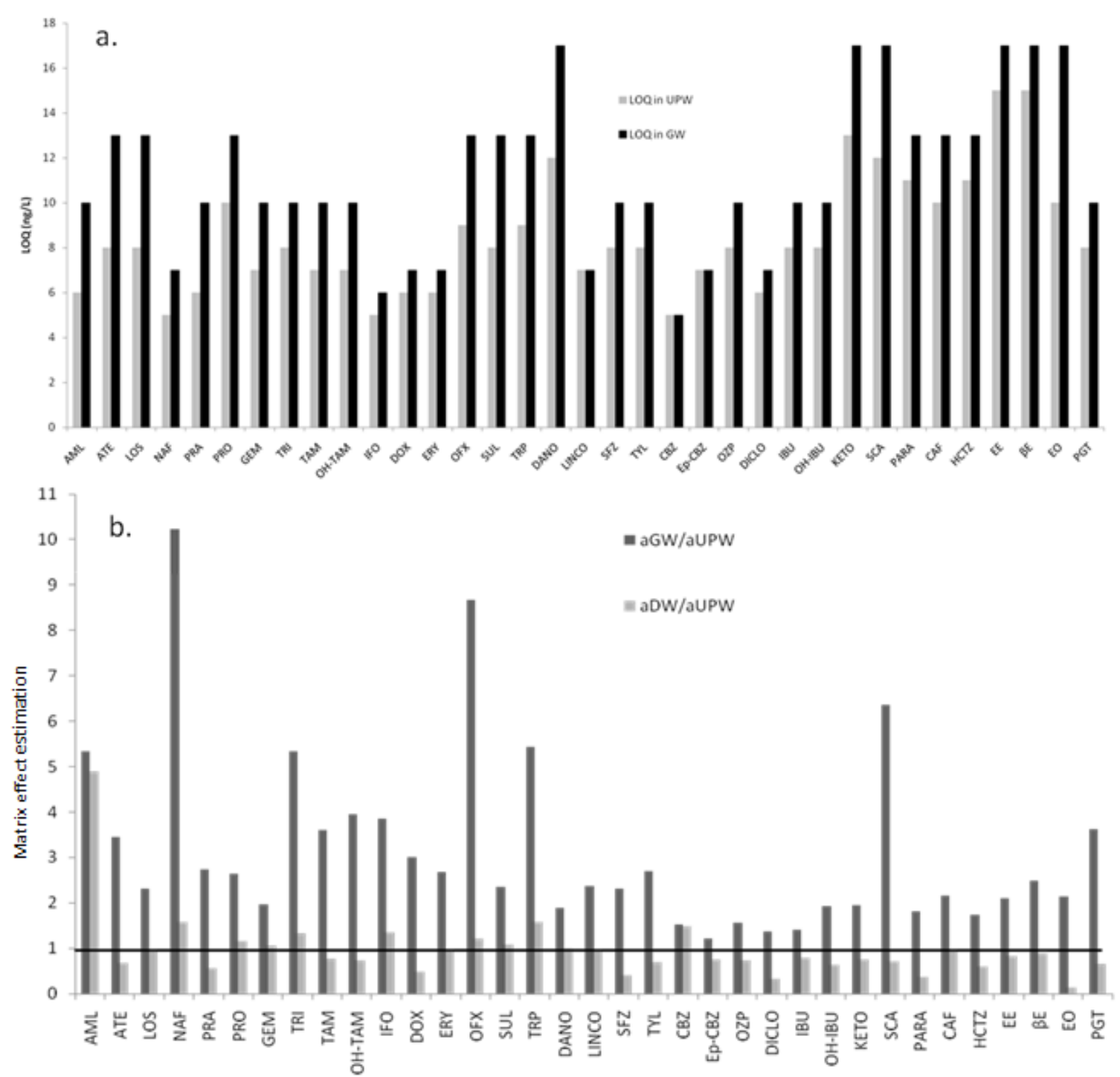

Figure 6: a. LOQ in UPW and GW for all molecules b. Matrix effects of all analytes

\subsection{Analysis of surface water and drinking water}

The developed method was used to determine the concentration of 37 pharmaceuticals

substances in inflow and outflow waters of 8 drinking water treatment plants (DWTP) in

west of France. The samples were collected once a month between october 2013 and april 
concentrations of 27 pharmaceuticals or metabolites in surface water as a box plot; this statistical representation summarizes the data, for each compound, by the mean values, median value, first and third quartiles and observed extrema. 7 molecules (PARA-GLU, KETO, OH-IBU, DANO, PARA, SCA, CAF) have a mean concentration greater than 50 ng.L-1. 10 molecules were quantifieded with mean concentrations higher than 10 ng. L $^{-1}$ (GEM, CBZ, DICLO, OZP, OFX, IBU, HCTZ, ATE, PRO and DOX). The last detected 10 molecules exhibit mean concentration lower than 10 ng.L-1 (SFZ, SUL, TRI, PRA, Ep-CBZ, TRP, EO, NAF, TYL, LOS). For some molecules, large differences between the extrema are observed (PARA-Glu, KETO, OH-IBU, SCA). These differences depend on the sampling date essentially. It should be underlined that median values are close to mean values indicating that extrema values do not play an important role. The maximum observed concentration in surface water was 650 ng. $\mathrm{L}^{-1}$ for KETO. Detection frequencies depend on compounds and range from $100 \%$ occurrence for CAF and PARA and 9\% for TYL. 13 molecules (PARA-Glu, KETO, OH-IBU, DANO, PARA, CAF, SCA, DICLO, GEM, CBZ, OZP, OFX and ATE) were quantified in more than $50 \%$ of surface water samples. In drinking water (figure 8), six molecules (KETO, PARA-Glu, $\mathrm{OH}-\mathrm{IBU}, \mathrm{DANO}, \mathrm{PARA}$ and CAF) were quantified in $90 \%$ or more of the drinking water samples. These 6 molecules were also the most quantified molecules in surface water. The overall mean concentration values are between 4 (OZP) and $327 \mathrm{ng} / \mathrm{L}$. The maximum concentration found was $650 \mathrm{ng} / \mathrm{L}$ for KETO. For drinking water, the same remark than for surface water may be made concerning the gap between minimum and maximum concentrations: the eight drinking water treatment plants operate different treatment chains with different type of water resources. 

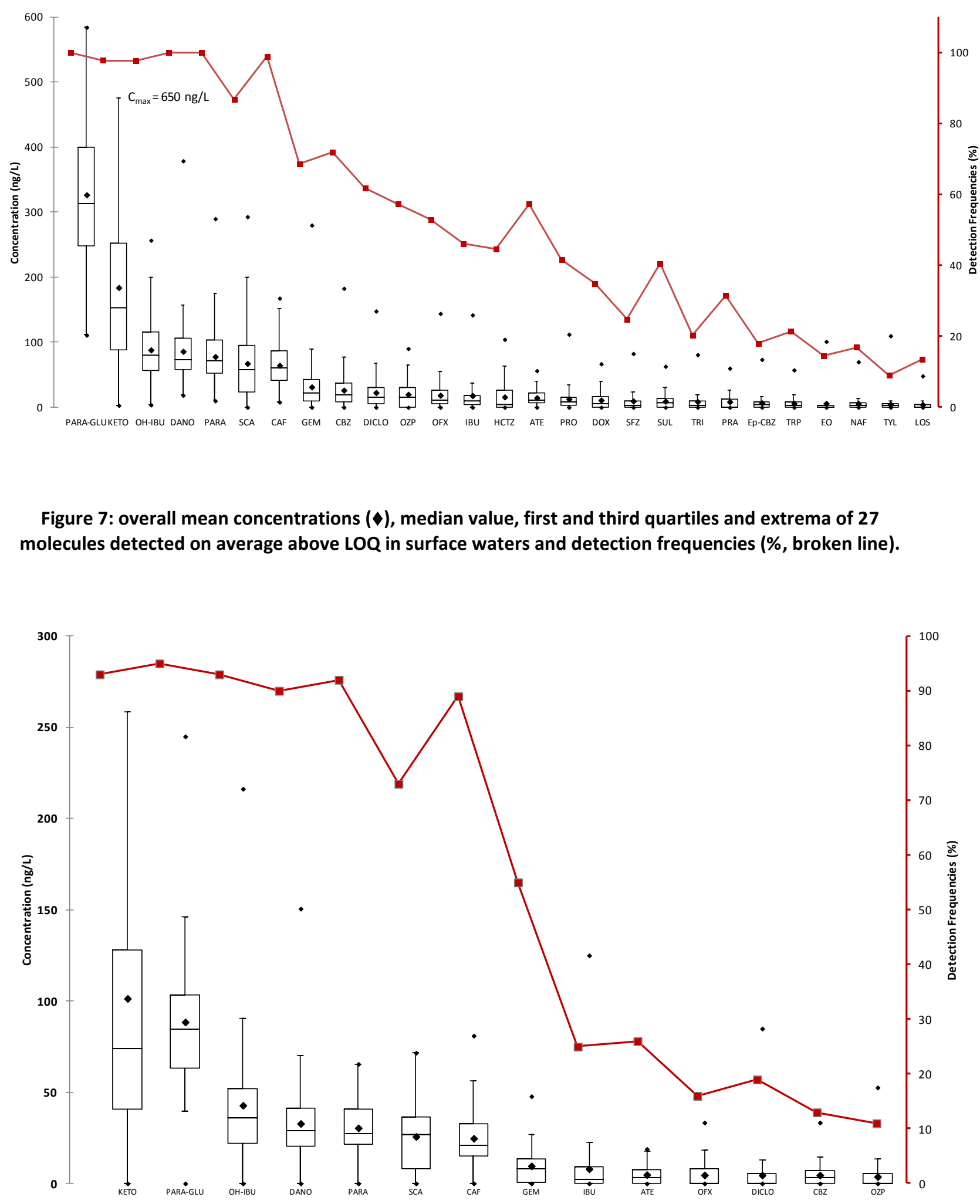
molecules detected in tap waters and detection frequencies $(\%$, broken line). 


\section{Conclusion}

A multiresidue analysis was developed using on-line solid phase extraction connected to liquid chromatography coupled with tandem mass spectrometry in order to quantify residue trace levels 35 pharmaceuticals compounds in surface and drinking water. The short implementation time needed to achieve the preconcentration and the analysis, 17 minutes for the positive mode method and 15 minutes for the negative mode method is among the most significant advantages of this method compared to off-line solid phase extraction. The developed method with a preconcentration factor of one thousand showed detection limits compatible with the study of environmental matrices with very low analyte concentrations. The limits of detection and quantification are between 1.5 and $4 \mathrm{ng} / \mathrm{L}$ and 4 and $17 \mathrm{ng} / \mathrm{L}$, respectively. Standard addition was chosen for the quantification of molecules in water samples to overcome the matrix effects and provide an accurate determination of targeted compounds. Among all studied substances, doxicycline appeared to be the most affected by a matrix effect. The developed methods were applied to eight surfaces and drinking water. In surface water, 12 molecules could be quantified in almost all analyzed samples with a maximum concentration value of $650 \mathrm{ng} / \mathrm{L}$ for Ketoprofen. In drinking water, 5 molecules could be regularly detected, with overall mean concentration values between 20 à 120ng/L.

\section{References:}

[1] Jorgensen, S.E., Halling-Sorensen, B., Drugs in the environment Chemosphere 40, 2000, 691.

[2] Gros, M., Rodriguez-Mozaz, S., Barceló, D. (2012). Fast and comprehensive multi-residue analysis of a broad range of human and veterinary pharmaceuticals and some of their metabolites in surface and treated waters by ultra-high-performance liquid chromatography 
coupled to quadrupole-linear ion trap tandem mass spectrometry. Journal of Chromatography A, 1248, 104- 121.

[3] Togola, A. and H. Budzinski (2008). Multi-residue analysis of pharmaceutical compounds in aqueous samples. Journal of Chromatography $A$ 1177(1), 150-158.

[4] Viglio, L., Aboulfald, K., Deneshvar, A., Prevost, M., Sauve, S. (2008). On-line solid phase extraction and liquid chromatography/tandem mass spectrometry to quantify pharmaceuticals, pesticides and some metabolites in wastewaters, drinking, and surface waters. J. Environ. Monit., 10, 482-489.

[5] Kim, S.D., Cho, J., Kim, I.S., Vanderford, B.J., Snyder, S.A. (2007). Occurrence and removal of pharmaceuticals and endocrine disruptors in South Korean surface, drinking, and waste waters. Water Research, 41, 1013-1021.

[6] Miege, C., Choubert, J.M., Ribeiro, L., Eusebe, M., Coquery, M. (2009). Fate of pharmaceuticals and personal care products in wastewater treatment plants - Conception of a database and first results. Environmental Pollution, 157, 1721-1726.

[7] Moldovan Z. (2006) Occurrences of pharmaceutical and personal care products as micropollutants in rivers from Romania. Chemosphere 64,1808-1817

[8] Mompelat, S., Le Bot, B., Thomas, O. (2009). Occurrence and fate of pharmaceutical products and by-products, from resource to drinking water. Environment International, 5, 803-814

[9] Stackelberg, P.E., Gibs, J., Furlong, E.T., Mayer, M.T., Zaugg, S.D., Lippincott, R. (2007). Efficiency of conventional drinking-water-treatment processes in removal of pharmaceuticals and other organic compounds. Science of the Total Environment, 377, 255272. 
[10] de Graaff, M.S., Vieno, N.M., Kujawa-Roeleveld, K., Zeeman, G., Temmink, H., Buisman, C.J.N., (2011). Fate of hormones and pharmaceuticals during combined anaerobic treatment and nitrogen removal by partial nitritation-anammox in vacuum collected black water. Water Research, 45 (1), 375.

[11] Daughton, C.G., Ternes, T.A.,(1999), Pharmaceuticals and personal care products in the environment: agents of subtle change? Environ. Health Perspect. 107, 907.

[12] Vieno, N.M., Tuhkanen, T., Kronberg, L. (2006). Analysis of neutral and basic pharmaceuticals in sewage treatment plants and in recipient rivers using solid phase extraction and liquid chromatography-tandem mass spectrometry detection. Journal of Chromatography A, 1134, 101-111

[13] Viglio, L., Aboulfald, K., Deneshvar, A., Prevost, M., Sauve, S. (2008). On-line solid phase extraction and liquid chromatography/tandem mass spectrometry to quantify pharmaceuticals, pesticides and some metabolites in wastewaters, drinking, and surface waters. J. Environ. Monit., 10, 482-489.

[14] Carlsson, C., Johansson, A.K., Alvan, G., Bergman, K., Kuhler, T., (2006) Are pharmaceuticals potent environmental pollutants? Part I: Environmental risk assessments of selected active pharmaceutical ingredients. Science of the Total Environment 364 (2006) 67 87.

[15] Cleuvers, M. (2003) Aquatic ecotoxicity of pharmaceuticals including the assessment of combination effects. Toxicology Letters 142, 185-194. 
[16] Gerrity, G., Gamage, S., Holady, S.J., Mawhinney, D.B., Quinones, O., Trenholma, R.A., Snyder, S.A., (2011). Pilot-scale evaluation of ozone and biological activated carbon for trace organic contaminant mitigation and disinfection, water research, 45, 2155-2165

[17] Rodriguez-Mozaz, S., Lopez de Alda, M.J., Barcelo, D., (2007). Advantages and limitations of on-line solid phase extraction coupled to liquid chromatography-mass spectrometry technologies versus biosensors for monitoring of emerging contaminants in water. Journal of chromatography A., 1152, 97-115.

[18] Trenholm, R., Vanderford, B., Snyder, S., (2009). On-line solid phase extraction LCMS/MS analysis of pharmaceutical indicators in water: A green alternative to conventional methods. Talenta, 79, 1425-1432.

[19] Miège, C., Favier,M., Brosse, C., Canler, J.P., Coquery, M.,(2006). Occurrence of betablockers in effluents of wastewater treatment plants from the Lyon area (France) and risk assessment for the downstream rivers. Talenta 70, 739-744.

[20] Postigo, C., Alda, M.J.L.D., Barcelo, D., (2008) Fully Automated determination in the low nanogram per liter level of defferent classes of drugs and abuse in sewage water by On-line solid-phase extraction-liquid-chromatography-electrospray-tandem mass spectrometry, Anal. Chem., 80, 3123-3134.

[21] Viglio, L., Aboulfadl, K., Mahvelat, A.D., Prevost, M., Sauve, S., (2008). On-line solid phase extraction and liquid chromatography/tandem mass spectrometry to quantify pharmaceuticals, pesticides and some metabolites in wastewaters, drinking, and surface waters, J. Environ. Monit. 10, 482-489. 
[22] Alnouti, Y., Srinivasan, K., Wadell, D., Bi, H., Kavetshaia, O., Gusev, A.I., (2005).

Development and application of a new on-line SPE system combined with LC-MS/MS detection for high throughput direct analysis of pharmaceutical compounds in plasma, Journal of Chromatography A. 1080, 99-106.

[23] Wang, S., Huang, W., Fang, G., He, J., Zhang, Y., (2008). On-line coupling of solid-phase extraction ti high-performance liquid chromatography for determination of eostrogens in environment, Anal. Chim. Acta 606, 194-201.

[24] Feitosa-Felizzola, J., Temime, B., Chiron, S., (2007). Evaluating on-line solid-phase extraction coupled to liquid chromatography ion trap mass spectrometry for reliable quantification and confirmation of several classes of antibiotics in urban wastewaters, Journal of Chromatography. A. 1164, 95-104.

[25] Van De Steene, J., Lambert, W., Comparison of matrix effects in HPLC-MS/MS and UPLCMS/MS analysis of nine basic pharmaceuticals in surface waters. Journal of The American Society for Mass Spectrometry 2008, 19 (5), 713.

[26] Swartz, M., Murphy, B. (2007). L’Ultra Performance LC: I'avenir de la chromatographie liquid. Les Technologie de laboratoire, n³ Mars-Avril, 20-22

[27] Cimetiere, N., Soutrel, I., Lemasle, M., Laplanche, A., Crocq, A. (2013) Environmental Technology, 34(22), 3031-3041

[28] Kasprzyk-Hordern, B., Dinsdale, R.M., Guwy, A.J., (2008). The effect of signal suppression and mobile phase composition on the simultaneous analysis of multiple classes of acidic/neutral pharmaceuticals and personal care products in surface water by solid-phase extraction and ultra-performance liquid chromatography-negative electrospray tandem mass spectrometry. Talanta, 74, 1299-1312 
426 [29] Balakrishnan, V.K., Terry, K.A, Toito, J., (2006). Determination of sulfonamide antibiotics

427 in wastewater: A comparison of solid phase microextraction and solid phase extraction 428 methods. Journal of Chromatography A, 113, 1-10. 